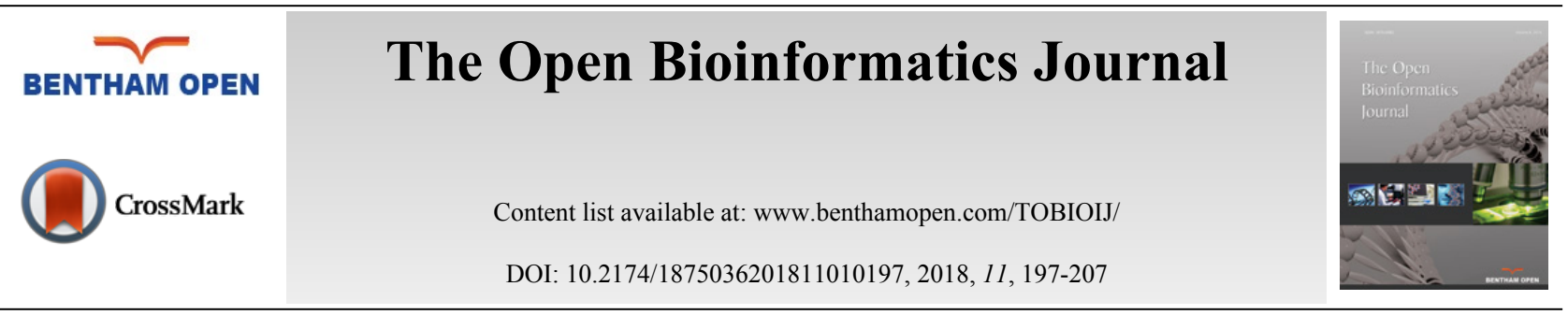

RESEARCH ARTICLE

\title{
Computational Pharmacogenetics of P-Glycoprotein Mediated Antiepileptic Drug Resistance
}

\author{
Sindhu Varghese ${ }^{1}$ and Ashok Palaniappan ${ }^{2, *}$ \\ ${ }^{\prime}$ Department of Allied Health Sciences, Chettinad Academy of Research and Education, Kelambakkam, Tamil Nadu \\ 603103, India \\ ${ }^{2}$ School of Chemical and Biotechnology, SASTRA Deemed University, Thanjavur, Tamil Nadu 613401, India
}

Received: April 21, 2018

Revised: July 12, 2018

Accepted: July 27, 2018

\begin{abstract}
:
Background:

The treatment of epilepsy using antiepileptogenic drugs is complicated by drug resistance, resulting in treatment failure in more than one-third of cases. Human P-glycoprotein (hPGP; MDRl) is a known epileptogenic mediator.

\section{Methods:}

Given that experimental investigations have suggested a role for pharmacogenetics in this treatment failure, it would be of interest to study hPGP polymorphisms that might contribute to the emergence of drug resistance. Changes in protein functional activity could result from mutations as well as altered abundance. Bioinformatics approaches were used to assess and rank the functional impact of 20 missense MDR1 polymorphisms and the top five were selected. The structures of the wildtype and variant hPGP were modelled based on the mouse PGP structure. Docking studies of the wildtype and variant hPGP with four standard anti-epileptic drugs were carried out.
\end{abstract}

\section{Results:}

Our results revealed that the drug binding site with respect to the wildtype protein was uniform. However, the variant hPGP proteins displayed a repertoire of binding sites with stronger binding affinities towards the drug.

\section{Conclusion:}

Our studies indicated that specific polymorphisms in MDR1 could drive conformational changes of PGP structure, facilitating altered contacts with drug-substrates and thus modifying their bioavailability. This suggests that MDRI polymorphisms could actively contribute to the emergence of pharmaco-resistance in antiepileptic therapy.

Keywords: P-glycoprotein, Drug-resistant epilepsy, MDR1 polymorphism, Structure-activity relationship, Docking, Homology modelling, Differential ligand affinity, Bioavailability.

\section{INTRODUCTION}

PGP (HGNC nomenclature: ABCB1) is a key transmembrane protein conserved from bacteria to man, and its function is to protect the organism from toxic xenobiotics. PGP has turned out to be a critical player in multiple drug resistance phenomena. Here, we are interested in its role in antiepileptic drug resistance. Epilepsy is a chronic neurological condition affecting more than 50 million people worldwide and $1-2 \%$ of the population [1]. The recurring limitation in the treatment protocol of epilepsy is the failure of drug-response in more than one-third of cases. This is the case with the $>30$ FDA-approved drugs for epilepsy. PGP is an ATP-coupled efflux pump documented as an

\footnotetext{
* Address correspondence to the author at the School of Chemical and Biotechnology, SASTRA Deemed University, Thanjavur, Tamil Nadu 613401,
} India; E-mail: apalania@scbt.sastra.edu 
epileptogenic mediator [2]. It is known to be highly expressed in the blood-brain barrier, which is pharmacologically crucial for the bioavailability of drugs acting on the central nervous system [3]. The experimental evidence for the role of PGP polymorphisms in antiepileptic drug resistance has not been conclusive so far [4 - 10]. There is evidence for its cognate role in antidepressant therapy [11]. There are at least two mechanisms by which PGP could mediate refractory epilepsy. First, elevated levels of PGP protein might be linked with the low intracellular drug concentration in cortical cells observed in epilepsy treatment. Elevated abundance could result from multiple mechanisms, for example, promoter sequence mutations, decrease in methylation-mediated epigenetic silencing, change in miRNA-mediated transcript abundance, and decrease the rate of protein degradation. PGP is well-known for its broad substrate specificity, and greater PGP abundance would result in phenotypic drug resistance due to effective drug extrusion. Alternatively, a gain-of-function mutation or changes in protein folding might enhance its functional activity, resulting in the same phenotype, i.e., hyperactive PGP leading to pharmacoresistant epilepsy (Fig. 1)[12, 13].

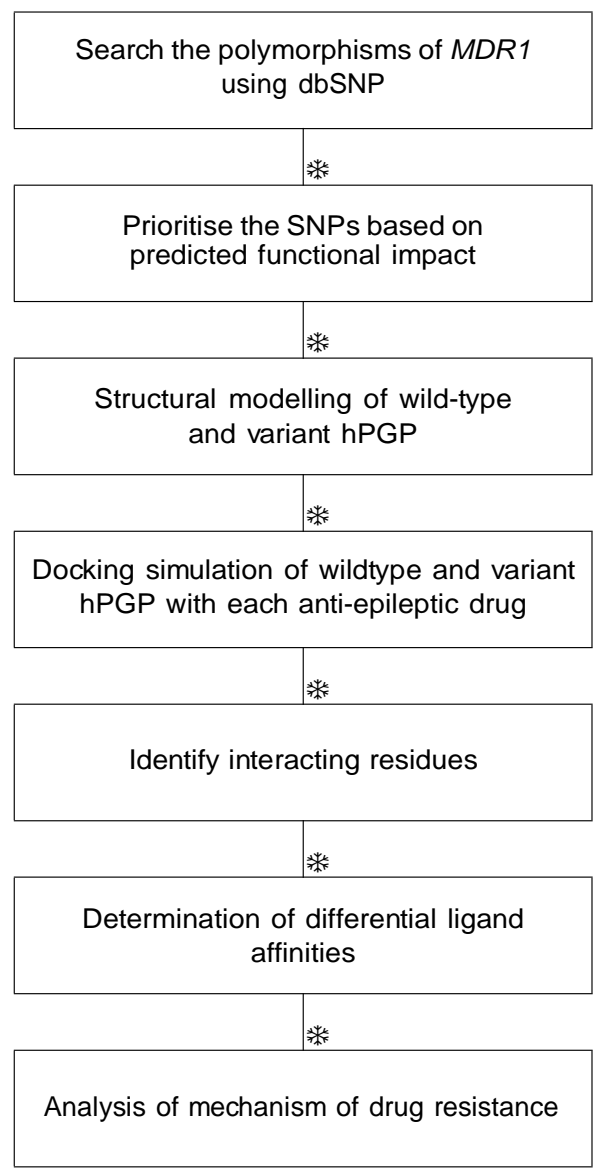

Fig. (1). Methodology for in silico study of MDR1 polymorphisms in pharmacoresistant epilepsy.

PGP consists of two homologous halves, each consisting of a transmembrane (TM) domain with six alpha helices and a Nucleotide-Binding Domain (NBD) [14]. A large, hydrophobic and polyspecific drug-binding pocket resides in the inverted V-shaped internal cavity formed by the transmembrane domains [15]. It is clear that he key to epilepsy treatment would involve control of the epileptogenic mediator proteins, including hPGP. Structural studies of hPGP might enhance our current understanding of the role of PGP in drug resistance mechanisms, and provide any evidence of the relationship between specific MDR1 haplotypes and altered drug pharmacokinetics. Given that little information is available on the pharmacology of missense polymorphisms of $M D R 1$, analysis of the role of gain-of-function muta tions in PGP would be valuable. Earlier bioinformatic studies of susceptible genetic Loci have identified and analyzed key polymorphisms specific to pathological phenotypes, for e.g., polymorphisms associated with methylenetetrahydrofolate reductase (MTHFR) gene [16 - 21]. Genetic polymorphisms are known to influence sus ceptibility to epilepsy (for e.g., BDNF [22, 23]). Here, we have attempted an in silico study of PGP polymorphisms and their structure-activity relationships with respect to drug-substrates to obtain a comprehensive picture of PGP role in the 
emergence of antiepileptic drug insensitivity. PGP-mediated processes are also the major con tributors to the emergence of drug resistance in cancer therapy and other conditions. Our results could extend to examining the role of Pglycoprotein in generalized drug-resistance in multiple conditions [24].

\section{MATERIALS AND METHODS}

\subsection{Polymorphism Analysis}

The hPGP sequence was retrieved from UniProt (acc. no. P08183). A PSI-BLAST search was performed using hPGP as query and target database as Vertebrates, with an E-value of 0.001 until convergence [25]. We selected top 5000 sequences from this result and clustered for redundancy at 40\% sequence identity [26]. Multiple align ment of all the hits was performed using ClustalX [27] and manually edited (available in Supporting Information). The dbSNP was to used to identify hPGP SNPs withs the search term: "human [orgn] AND missense AND PGP". The hits were assessed for the functional impact of polymorphisms using the curated multiple alignments obtained above. Three different tools were used: SIFT [28], PolyPhen2 [29], and PhD SNP [30]. Consensus of these predictions was used to evaluate the functionally important SNPs.

\subsection{Homology Modeling}

The template structures were retrieved using a Blast search of hPGP against the PDB database [31]. ClustalX was used to align the template and hPGP (i.e., target). Modellerv9 was used for modelling and energy-minimisation [32]. For each target, five separate models were generated and the model with the least DOPE (discrete optimized potential energy) score was chosen as the best model. The structure of a variant protein could be obtained by modeling in the mutation on the wild-type structure, however, this would not model any global effects due to the mutation. In order to fully account for the effects of the mutation, we modelled the variant proteins independently of the wildtype protein. Molprobity was used to validate the models obtained [33].

\subsection{Protein and Ligand Preparation}

Autodock 4.2 suite of tools was used for carrying out the docking simulations of hPGP variants and anti-epileptic drugs $[34,35]$. Hydrogen atoms missing in the protein were added. This was followed by the addition of partial charges to the atoms. The protein was then converted to PDBQT format. The SMILES notation of the drugs of interest was retrieved from Pubchem [36]. The PDB co-ordinates of the drugs of interest were generated from their SMILES representation using OpenBabel [37]. To generate the conformers of each drug, we used MGLtools by calculating the number of bond torsions in the 3D structure. The ligand was then converted to the PDBQT format as well using AutoDock Tools. Target affinity maps for each atom type in the ligand were generated by autogrid by defining a uniform grid box centered in the hPGP internal cavity. This procedure was repeated for each target-ligand pair, for a total of $6 \times 4=24$ times.

\subsection{Docking}

We employed the Lamarckian genetic algorithm with default parameters for docking search, with 2,500,000 cycles per run, and 10 runs per receptor-ligand pair. The binding mode with the least binding energy was defined as the best pose. The ten poses obtained for each receptor-ligand pair were clustered at $2.0 \AA$ r.m.s. to validate the convergence to the best pose. The docked complex was then loaded in PDBQT format, converted to PDB coordinates using OpenBabel, and finally visualized using Rasmol2.7 [38]. The differential affinity of the variant for a given ligand relative to the wildtype was estimated as the difference in the binding energies, i.e. $\Delta \Delta \mathrm{G}_{\mathrm{mut}}=\Delta \mathrm{G}_{\mathrm{bind,mut}}-\Delta \mathrm{G}_{\mathrm{bind}, \mathrm{w}}$.

\section{RESULTS}

Nearly 500 hPGP SNPs were retrieved, however most of these were unannotated, and we obtained a set of $20 \mathrm{hPGP}$ SNPs for further study, none of whose functional effects were known in the literature (Table 1). The results of our assessment of functional impact by various approaches are summarised in Table 2. Most of the SNPs were determined to be neutral, not disease-causing or deleterious. Five SNPs were predicted to be functionally important by at least one of the tools, as shown in Table 2. 
Table 1. Missense SNPs of human PGP and their location. SNPs are represented in the usual convention: wildtype aminoacid followed by position followed by replacement aminoacid.

\begin{tabular}{|c|c|c|c|}
\hline No. & rsid & SNP & Location \\
\hline 1 & rs 28381804 & F17L & $\mathrm{N}$-terminal domain \\
\hline 2 & rs9282564 & $\mathrm{N} 21 \mathrm{D}$ & N-terminal domain \\
\hline 3 & rs 1202183 & $\mathrm{~N} 44 \mathrm{~S}$ & TM1 \\
\hline 4 & rs9282565 & $\mathrm{A} 80 \mathrm{E}$ & Linker between TM1 and TM2 \\
\hline 5 & $r s 1128501$ & G185V & TM3 \\
\hline 6 & rs 36008564 & $\mathrm{I} 261 \mathrm{~V}$ & Linker between TM4 and TM5 \\
\hline 7 & rs2229109 & S400N & NBD1 \\
\hline 8 & $r s 28381902$ & E566K & NBD1 \\
\hline 9 & $r s 28381914$ & $\mathrm{R} 593 \mathrm{C}$ & NBD1 \\
\hline 10 & rs2235036 & A599T & NBD1 \\
\hline 11 & rs 35023033 & R669C & NBD1 \\
\hline 12 & rs2235039 & V801M & Linker between TM8 and TM9 \\
\hline 13 & rs2032581 & $\mathrm{I} 829 \mathrm{~V}$ & TM9 \\
\hline 14 & rs 28381967 & $\mathrm{I} 836 \mathrm{~V}$ & TM9 \\
\hline 15 & rs2032582 & S893A & Linker between TM11 and TM12 \\
\hline 16 & $r s 72552784$ & A999T & NBD2 \\
\hline 17 & rs 28401798 & P1051A & NBD2 \\
\hline 18 & $r s 55852620$ & Q1107P & NBD2 \\
\hline 19 & rs2229107 & S1141T & NBD2 \\
\hline 20 & rs 28364274 & V1251I & NBD2 \\
\hline
\end{tabular}

Table 2. Topranked polymorphisms based on consensus prediction of functional impact.

\begin{tabular}{|c|c|c|c|c|c|c|c|}
\hline No. & SNP & PolyPhen2 Prediction & PolyPhen2 Probability & $\begin{array}{c}\text { SIFT } \\
\text { Prediction }\end{array}$ & $\begin{array}{c}\text { SIFT } \\
\text { Score }\end{array}$ & $\begin{array}{c}\text { phdsnp } \\
\text { Prediction }\end{array}$ & $\begin{array}{c}\text { phdsnp } \\
\text { Reliability }\end{array}$ \\
\hline 1 & G185V & Prob. Damaging & 1 & Damaging & 1 & Disease & 8 \\
\hline 2 & R593C & benign & 0.392 & Damaging & 1 & Disease & 6 \\
\hline 3 & E566K & Prob. Damaging & 1 & Damaging & 0.88 & Disease & 6 \\
\hline 4 & Q1107P & Prob. Damaging & 0.962 & tolerated & 0.19 & Disease & 6 \\
\hline 5 & A999T & Poss. Damaging & 0.465 & tolerated & 1 & Neutral & 7 \\
\hline
\end{tabular}

Table 3 provides the representative structures of P-glycoprotein in the PDB. Of these homologous hits, the mouse structures cover the full length of the hPGP. Some mouse structures co-crystallised with a ligand might not be representative of the native PGP conformation. When $4 \mathrm{Q} 9 \mathrm{H}$ was superimposed with the $3 \mathrm{G} 5 \mathrm{U}$ structure, it was observed that the register of the C-terminal half of the 'inverted-V' of 4Q9H was displaced relative to that of $3 \mathrm{G} 5 \mathrm{U}$ (Fig. 2), which rendered 4Q9H unsuitable for modeling the full hPGP structure. The alignment between the hPGP and 3G5U is very good, showing $>87.5 \%$ sequence identity and good sequence coverage (Fig. 3). 3G5U was used as the template for homology modeling. The target structures of the hPGP wildtype and the five variants were independently modeled and energy- minimised five times each, and the best model was used for further studies. All the modelled structures are available in the Supporting Information and their mutual rms deviations are shown in Table 4.

Table 3. Crystal structures of PGP homologues.

\begin{tabular}{|c|c|c|c|c|c|}
\hline pdbid & Organism & Chains & Length & Res. A & \#TM helices \\
\hline 3G5U & Mus musculus & $A, B$ & 1284 & 3.80 & 12 \\
\hline 4Q9H & Mus musculus & $A$ & 1284 & 3.40 & 12 \\
\hline $4 \mathrm{KSB}$ & Mus musculus & $A$ & 1284 & 3.80 & 12 \\
\hline 3G61 & Mus musculus & $A, B$ & 1284 & 4.35 & 12 \\
\hline $3 \mathrm{G} 60$ & Mus musculus & $A, B$ & 1284 & 4.40 & 12 \\
\hline $4 \mathrm{KSC}$ & Mus musculus & $A$ & 1284 & 4.00 & 12 \\
\hline 4LSG & Mus musculus & $A, B$ & 1284 & 3.80 & 12 \\
\hline $4 \mathrm{M} 1 \mathrm{M}$ & Mus musculus & $A, B$ & 1282 & 3.80 & 12 \\
\hline
\end{tabular}


(Table 3) contd.....

\begin{tabular}{|c|c|c|c|c|c|}
\hline pdbid & Organism & Chains & Length & Res. A & \#TM helices \\
\hline 2HYD & Staphylococcus aureus & $A, B$ & 578 & 3.00 & 6 \\
\hline $3 \mathrm{~B} 5 \mathrm{Z}$ & Salmonella enterica & $A, B, C, D$ & 582 & 4.20 & 5 \\
\hline $3 \mathrm{WME}$ & Cyanidioschyzon merolae & $A$ & 612 & 2.75 & 3 \\
\hline
\end{tabular}

Table 4. Mutual rms deviation of the template and modelled structures (in $\AA$ ). Variant numbering corresponds to the order in Table 2.

\begin{tabular}{|c|c|c|c|c|c|c|}
\hline- & 3g5u & wt & Mut1 & Mut2 & Mut3 & Mut4 \\
\hline wt & 4.51 & - & - & - & - & - \\
\hline Mut1 & 4.24 & 0.53 & - & - & - & - \\
\hline Mut2 & 4.43 & 0.62 & 1.31 & - & - & - \\
\hline Mut3 & 4.32 & 0.71 & 1.19 & 1.33 & - & - \\
\hline Mut4 & 4.33 & 0.43 & 0.97 & 0.81 & 0.59 & - \\
\hline Mut5 & 4.63 & 0.49 & 0.71 & 1.04 & 0.48 & 0.44 \\
\hline
\end{tabular}

Phenobarbital was first used as an antiseizure drug in 1912, followed by phenytoin. Today, more than 30 drugs are FDA-approved in the treatment of epilepsy, yet all of them face pharmacoresistance and more than one-third of epilepsy cases remain untreatable. In addition to phenobarbital and phenytoin, two other common antiepileptic medications, namely valproate and carbamazepine, were included in the set of ligands studied (Table 5).

Table 5. Anti-epileptic drugs.

\begin{tabular}{|c|c|c|c|}
\hline No. & Drug & Pubchemid & Smiles Notation \\
\hline 1 & Valproate & 3121 & $\mathrm{CCCC}(\mathrm{CCC}) \mathrm{C}(=\mathrm{O}) \mathrm{O}$ \\
\hline 2 & Phenytoin & 1775 & $\mathrm{C} 1=\mathrm{CC}=\mathrm{C}(\mathrm{C}=\mathrm{C} 1) \mathrm{C} 2(\mathrm{C}(=\mathrm{O}) \mathrm{NC}(=\mathrm{O}) \mathrm{N} 2) \mathrm{C} 3=\mathrm{CC}=\mathrm{CC}=\mathrm{C} 3$ \\
\hline 3 & Carbamazepine & 2554 & $\mathrm{C} 1=\mathrm{CC}=\mathrm{C} 2 \mathrm{C}(=\mathrm{C} 1) \mathrm{C}=\mathrm{CC} 3=\mathrm{CC}=\mathrm{CC}=\mathrm{C} 3 \mathrm{~N} 2 \mathrm{C}(=\mathrm{O}) \mathrm{N}$ \\
\hline 4 & Phenobarbital & 4763 & $\mathrm{CCC} 1(\mathrm{C}=\mathrm{O}) \mathrm{NC}(=\mathrm{O}) \mathrm{NC} 1=\mathrm{O}) \mathrm{C} 2=\mathrm{CC}=\mathrm{CC}=\mathrm{C} 2$ \\
\hline
\end{tabular}

Docking between each hPGP protein (wildtype +5 variants) and ligand was carried out. Ten docking runs were performed per receptor-ligand pair. Each run provides one low-energy docked conformation of the respective receptorligand pair. The site corresponding to the least-energy binding mode was taken as the binding site of the ligand with the receptor. To ascertain convergence to the lowest-energy binding mode, the ten runs of each receptor-ligand binding conformations were clustered at $2.0 \AA$ r.m.s. The lowest-energy binding modes showed good convergence. Of the 24 receptor-ligand pairs, 21 had energy-histograms showing the least binding energy $( \pm 0.2 \mathrm{kcal} / \mathrm{mol})$ as the most probable conformation and the least binding energies of the rest were within $1 \mathrm{kcal} / \mathrm{mol}$ of the binding energies of the most probable conformation. This provided confidence that the docking procedure resulted in convergence to the optimum receptor-ligand conformation. The structures of the receptor-drug complexes, as well as the best poses (defined as within $4.5 \AA$ of the ligand), are available in the Supporting Information. A comparison of the best poses between the wildtype and one of the variants is illustrated in Fig. (4). The groups of contacting residues specific to each docked complex are shown in Table 6. These residues were defined at a contact distance of $<4.5 \AA$ from the drug in the bound conformation. The summary of the docking analysis is presented in Table 7.

Table 6. Contacting residues of the receptor within $4.5 \AA$ of the ligand in the best pose of each docked ligand-receptor pair. Residue numbering follows the UniProt human PGP entry P08183.

\begin{tabular}{|c|c|c|}
\hline Receptor & Ligand & Interacting Residues \\
\hline Wildtype & Drug1 & Leu244,Tyr247,Arg286,Ile289,Lys290,Ile293,Ala823,Lys826 \\
\hline Wildtype & Drug2 & Gly141,Ile144,His145,Arg148,Val179,Ser180,Asn183,Asp886,Leu890,Leu924,Pro927,Tyr928,Ser931,Lys934 \\
\hline Wildtype & Drug3 & Gly141,Ile144,His145,Arg148,Val179,Ser180,Asn183,Asp886,Leu890,Leu924,Pro927,Tyr928,Ser931,Lys934 \\
\hline Wildtype & Drug4 & Met701,Asn704,Leu705,Trp708,Ile829,Arg832,Leu833 \\
\hline G185V & Drug1 & Thr422,Leu554,Gln556,Ala557,Thr558,Gln570,Leu573,Asp574,Arg577,Val584,Thr591,Val592,Asn594,Ala595 \\
\hline G185V & Drug2 & Ile199,Phe303,Tyr307,Asn721,Leu724,Gln725,Ser766,Gln838,Met986,Ala987,Gln990,Val991,Phe994 \\
\hline G185V & Drug3 & Ile199,Phe303,Tyr307,Asn721,Leu724,Gln725,Ser766,Gln838,Ala987,Gln990,Va1991,Phe994 \\
\hline G185V & Drug4 & Lys291,Ala292,Asn296,Gln773,Phe777,Gly778,Glu782,Lys826,Ser831,Phe994,Ala995,Pro996 \\
\hline R593C & Drug1 & Leu244,Tyr247,Lys285,Arg286,Ile289,Lys290,Ile293,Thr785,Lys826 \\
\hline R593C & Drug2 & Thr627,Met628,Gln629,Thr630,Leu688,Phe804,Pro807,Lys808,Asn809,Thr810,Thr811 \\
\hline
\end{tabular}


(Table 6) contd.....

\begin{tabular}{|c|c|c|}
\hline Receptor & Ligand & Interacting Residues \\
\hline R593C & Drug3 & Gln132,Val133,Trp136,Ile190,Glu875,Leu879,Phe938,Thr941,Phe942 \\
\hline R593C & Drug4 & Gln132,Val133,Trp136,Ile190,Glu875,Leu879,Phe938,Gly939,Thr941,Phe942 \\
\hline E566K & Drug1 & Leu244,Tyr247,Lys285,Arg286,Ile289,Lys290,Ile293,Thr785,Lys826 \\
\hline E566K & Drug2 & Gln132,Val133,Trp136,Cys137,Gly187,Ile190,Glu875,Leu879,Phe938,Thr941,Phe942 \\
\hline E566K & Drug3 & Ile293,Phe777,Gly778,Gly781,Ala823,Gln824,Lys826,Gly827,Ile829,Gly830,Phe994,Ala995,Pro996 \\
\hline E566K & Drug4 & Ser831,Ala834,Val835,Gln838,Gln990,Val991,Ser992,Ser993,Phe994,Ala995,Pro996,Asp997,Tyr998 \\
\hline Q1107P & Drug1 & Tyr247,Glu282,Arg286,Lys290,Gly781,Glu782,Thr785,Arg789,Ala823,Gln824,Lys826 \\
\hline Q1107P & Drug2 & Asp689,Glu690,Ser691,Ile692,Lys808,Asn809,Ala813,Leu814,Thr816,Arg817,His1007,Met1010,Ile1011 \\
\hline Q1107P & Drug3 & Val133,Trp136,Cys137,Glu875,Leu879,Lys934,Phe938,Thr941,Phe942 \\
\hline Q1107P & Drug4 & Ser831,Ala834,Va1835,Gln838,Gln990,Va1991,Ser992,Ser993,Phe994,Ala995,Pro996,Asp997,Tyr998 \\
\hline A999T & Drug1 & Leu244,Tyr247,Glu282,Arg286,Ile289,Lys290,Ile293,Thr785,Arg789,Ala823,Lys826 \\
\hline A999T & Drug2 & Ala259,Ala260,Ile261,Arg262,Thr630,Leu688,Phe804,Pro807,Lys808,Asn809,Thr810,Thr811,Leu814 \\
\hline A999T & Drug3 & Ser831,Ala834,Val835,Gln838,Gln990,Va1991,Ser993,Phe994,Ala995,Pro996,Asp997,Tyr998 \\
\hline A999T & Drug4 & Ser831,Ala834,Val835,Gln838,Gln990,Va1991,Ser992,Ser993,Phe994,Ala995,Pro996,Asp997,Tyr998 \\
\hline
\end{tabular}

Table 7. Free energies of binding $\left(\Delta G_{b i n d}\right)$ of each docked receptor-drug pair. The predicted differential ligand affinity is given by $\Delta \Delta G_{m u t}=\Delta G_{\text {bind,mut }}-\Delta G_{\text {bind,wt }}$. All values in $\mathrm{kcal} / \mathrm{mol}$.

\begin{tabular}{|c|c|c|c|c|}
\hline Receptor & Valproate & Phenytoin & Carbamazepine & -6.35 \\
\hline wildtype & -4.28 & -5.48 & -6.27 & -5.24 \\
\hline G185V & -3.90 & -6.38 & -6.37 & -5.62 \\
\hline R593C & -5.21 & -5.52 & -5.55 & -6.74 \\
\hline E566K & -5.53 & -6.17 & -6.67 & -6.15 \\
\hline Q1107P & -5.50 & -5.65 & -0.08 & -0.02 \\
\hline A999T & -5.15 & -0.90 & -0.38 \\
\hline$\Delta \Delta G_{G 185 V}$ & 0.38 & -0.04 & -0.5 \\
\hline$\Delta \Delta G_{R 593 C}$ & -0.93 & -0.69 & -0.80 \\
\hline$\Delta \Delta G_{E 566 K}$ & -1.25 & 0.01 & -0.31 \\
\hline$\Delta \Delta G_{Q 1107 P}$ & -1.22 & -0.17 & -0.32 \\
\hline$\Delta \Delta G_{A 999 T}$ & -0.87 & -0.28 & -1.24 \\
\hline
\end{tabular}

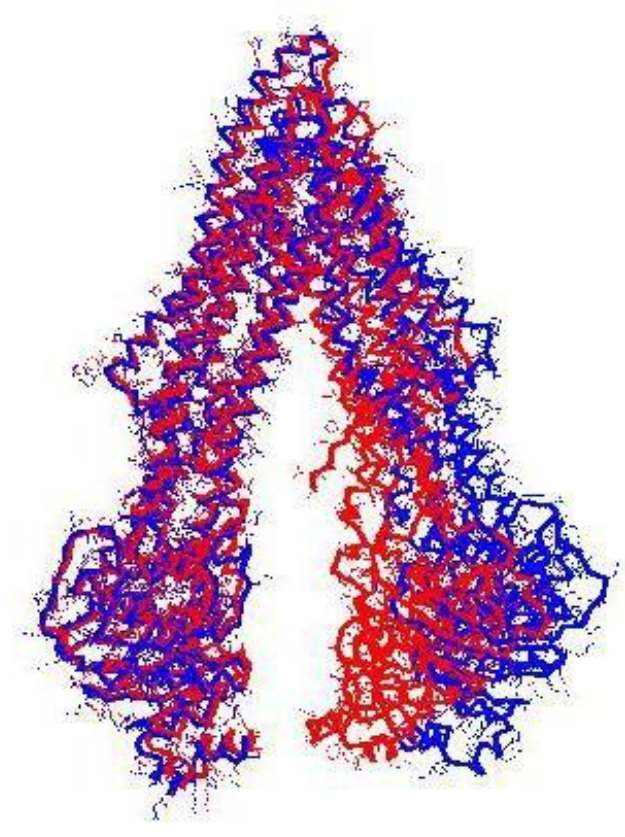

Fig. (2). Structural superposition of 3G5U (red) and 4Q9H (blue). Note the displacement of the C-terminal region of 4Q9H. 


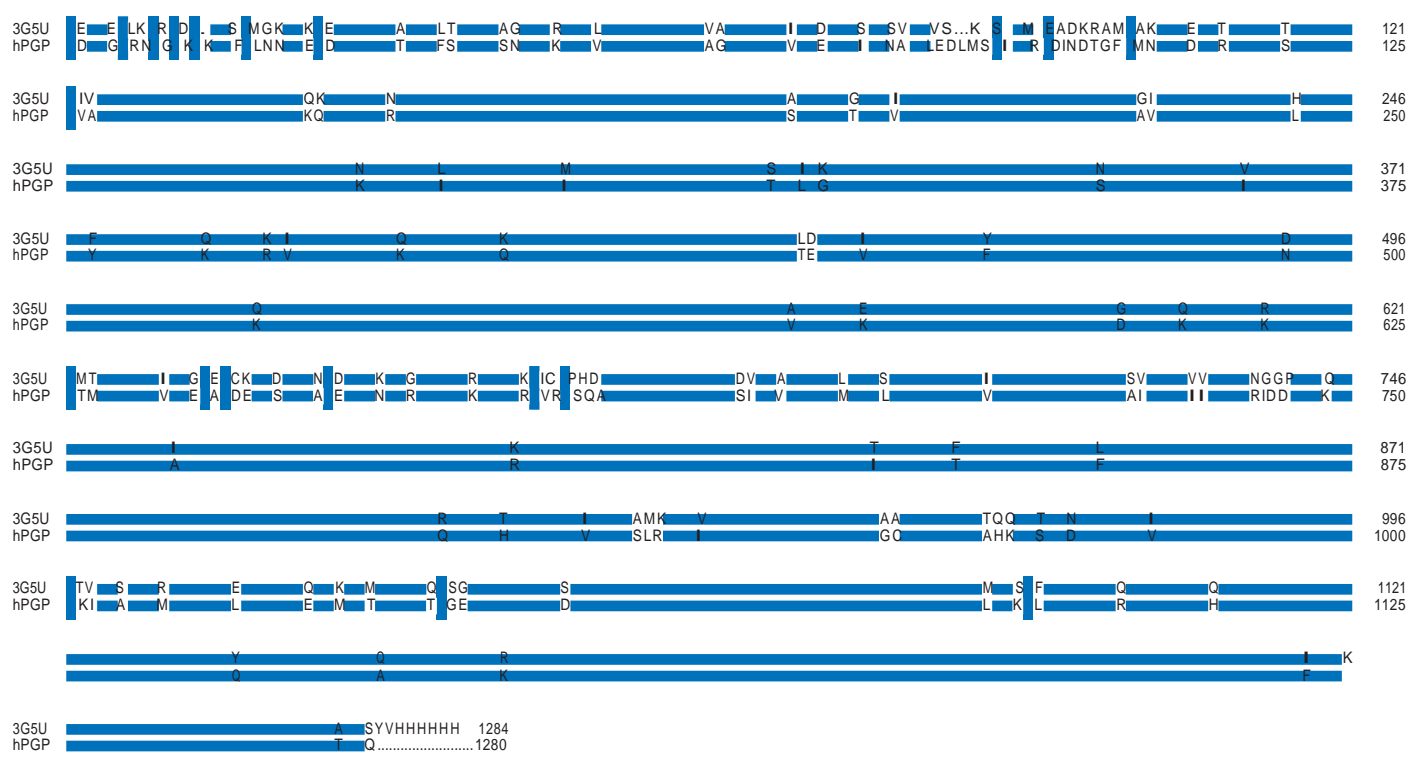

Fig. (3). Alignment of human PGP (target) and mouse 3G5U (template). Identical residues are highlighted and gaps are indicated by.

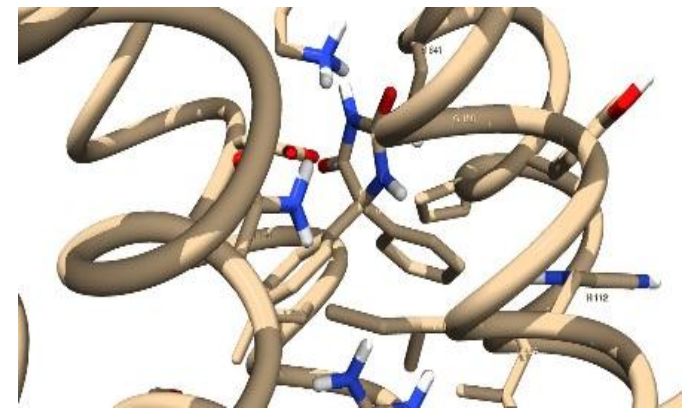

(a) Best pose of the wildtype hPGP with phenytoin

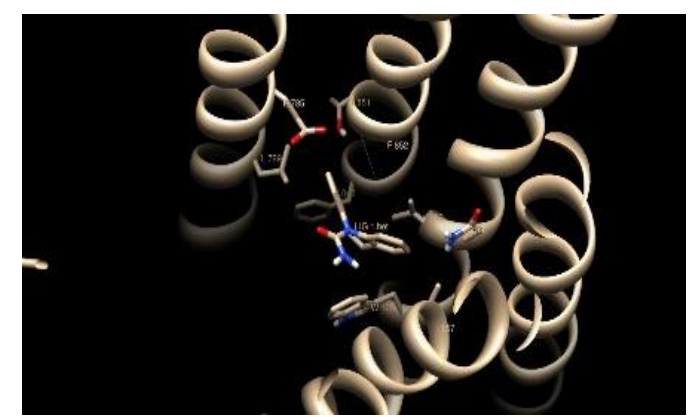

(b) Best pose of mutant R593C with carbamazepine

Fig. (4). Illustration of best pose comparisons.

\section{DISCUSSION}

The evolutionary conservation of the location of the prioritised SNPs was computed using the multiple alignments constructed from PGP homologous sequences non-redundant at $40 \%$ sequence identity. The quantile scores of each position with respect to hPGP sequence are given in the Supporting information. All five polymorphism locations ranked at least in the $50^{\text {th }}$ quantile, and the $\mathrm{E} 566 \mathrm{~K}$ in particular ranked $97^{\text {th }}$. The polymorphisms were found in evolutionarily conserved positions. Experimental evidence is available on some of the polymorphisms [39 - 41].

The hPGP residues binding the ligand in each hPGP-drug pair represent the drug-specific binding pocket (Table 6). These residues contributed to stabilizing the docked complex by forming hydrogen bonds and Van der Waals interactions with the substrates. It is observed that the binding site of wildtype hPGP is identical for phenytoin and carbamazepine. This is a 14-residue binding pocket in the internal cavity lined by four hydrophobic residues (Ile144, Val179, Leu890, Leu924), three charged residues (Arg148, Asp886, Lys934) and four polar residues (Ser180, Asn183, Tyr928, Ser931). In contrast, the variant proteins bound the drugs in alternative variable regions, notably a binding pocket involving Gln132, Val133, Trp136, Ile190, Glu875, Leu879, Phe938, Thr941, and Phe942 that bound all drugs except valproate. It was remarkable that for a given variant hPGP, the binding pocket interactions differed for each drug. The R593C hPGP variant bound phenytoin very close to the mutation site, suggesting evidence for a local conformational change in binding the drug.

Further clarity on these observations could be obtained on an examination of the estimated binding free energies of 
the wildtype and variant hPGPs with the different drugs of interest and the corresponding predicted differential ligand affinity given by $\Delta \Delta \mathrm{G}_{\text {mut }}=\Delta \mathrm{G}_{\text {bind,mut }}-\Delta \mathrm{G}_{\text {bind,wt }}$ (Table 7). It was observed that all but three of the differential ligand affinities were negative. This implied that the variant hPGP bound each drug with a stronger affinity than the wildtype hPGP. The maximum range of differential response was observed with variant E566K $\left(-1.25 \mathrm{kcal} / \mathrm{mol}_{<}<\Delta \Delta \mathrm{G}_{\mathrm{mut}}<0.80\right.$ $\mathrm{kcal} / \mathrm{mol})$.

Two features indicated the neutrality of wildtype hPGP with respect to binding anti-epileptic drugs. First, the binding pocket appeared constant for both phenytoin and carbamazepine. Second, the binding energy with the drug was higher relative to the variants and hence less tight. On the other hand, there were two features that indicated that variant hPGPs would assist in the development of drug resistance.

First, variant hPGPs bound each drug in a different location in the internal cavity. Variability in location affords a better search of the optimal binding modes of the drug. Second, consistently lower binding energies were observed, implying stable drug-PGP complexes for possible energetic extrusion of the drug. The in silico analysis showed that polymorphisms could have played a role in relocating the optimal drug-binding cavity for a higher affinity, relative to the wild-type hPGP.

An elevated affinity between a variant hPGP and the drug could suggest a potential differential adverse response to therapy. From Table 7, it is observed that this is the case for 17 out of the 20 drug-protein combinations studied. Experimental studies are necessary to validate these results and determine whether the mag nitude of any differential adverse responses could translate to the threshold for the development of pharmacoresistance. By contributing to drug resistance, PGP polymorphisms could conceivably play an adverse role in the treatment of multiple epilepsy subtypes. One example is electrical status epilepticus during slow sleep ('ESES'), a condition which could primarily affect children [42] and should best be treated early. The response to use of valproate and diazepam treatment regimens for ESES is quite heterogeneous [43 - 45], indicating inter-individual variability and a possible role for polymorphisms of pharmacogenomic importance, including those of PGP analyzed in our study.

\section{CONCLUSION}

Though hPGP is well-documented as a modifier of drug bioavailability in many conditions, its role in antiepileptic drug resistance has been controversial. At least two alternative mechanisms could explain the hPGP-mediated epileptogenic phenotype. Our work suggests that polymorphisms are a viable mechanism of PGP action that could lead to drug resistance acquisition independent of other mechanisms. It is interesting that all the polymorphisms appeared to result in gain-of-function. Coupled with the observation that somatic mutations could have a similar effect to identical inherited polymorphisms, this would suggest that PGP is a potential oncogene in the context of cancer drug resistance.

Developing a drug resistance strategy to combat drug resistance is a top priority. Our work has highlighted that MDR1 polymorphisms could potentially lower the threshold for development of pharmacoresistance. This gain-offunction process in hPGP offers a novel candidate target in the fight against antiepileptic drug re sistance. Experimental validation of our work is necessary to apply our findings towards achieving pharmacosensitive response in epilepsy treatment. Our methodology is extendable to studies investigating the effect of genetic polymorphisms on phenotypes in other diseases and conditions.

\section{AUTHORS' CONTRIBUTION}

Dr. Ashok Palaniappan conceived and designed the experiments. Experiment was performed and data was analyzed by Ms. Sindhu Varghese and Dr. Ashok Palaniappan. Dr. Ashok Palaniappan prepared the figures and/or tables.

Dr. Ashok Palaniappan drafted the work and revised it critically for important content.

\section{ETHICS APPROVAL AND CONSENT TO PARTICIPATE}

Not applicable.

\section{HUMAN AND ANIMAL RIGHTS}

No animals/humans were used for studies that are the basis of this research.

\section{CONSENT FOR PUBLICATION}

Not applicable. 


\section{CONFLICT OF INTEREST}

The authors declare no conflict of interest, financial or otherwise.

\section{ACKNOWLEDGMENTS}

Declared none.

\section{SUPPLEMENTARY MATERIAL}

Supplementary material is available on the publishers Website along with the published article.

\section{REFERENCES}

[1] Tishler DM, Weinberg KI, Hinton DR, Barbaro N, Annett GM, Raffel C. MDR1 gene expression in brain of patients with medically intractable epilepsy. Epilepsia 1995; 36(1): 1-6. [http://dx.doi.org/10.1111/j.1528-1157.1995.tb01657.x] [PMID: 8001500]

[2] Varvel NH, Jiang J, Dingledine R. Candidate drug targets for prevention or modification of epilepsy. Annu Rev Pharmacol Toxicol 2015; 55: $229-47$ [http://dx.doi.org/10.1146/annurev-pharmtox-010814-124607] [PMID: 25196047]

[3] Schinkel AH. P-Glycoprotein, a gatekeeper in the blood-brain barrier. Adv Drug Deliv Rev 1999; 36(2-3): 179-94. [http://dx.doi.org/10.1016/S0169-409X(98)00085-4] [PMID: 10837715]

[4] Ruth A, Stein WD, Rose E, Roninson IB. Coordinate changes in drug resistance and drug-induced conformational transitions in alteredfunction mutants of the multidrug transporter P-glycoprotein. Biochemistry 2001; 40(14): 4332-9. [http://dx.doi.org/10.1021/bi001373f] [PMID: 11284689]

[5] Siddiqui A, Kerb R, Weale ME, et al. Association of multidrug resistance in epilepsy with a polymorphism in the drug-transporter gene ABCB1. N Engl J Med 2003; 348(15): 1442-8. [http://dx.doi.org/10.1056/NEJMoa021986] [PMID: 12686700]

[6] Pedley TA, Hirano M. Is refractory epilepsy due to genetically determined resistance to antiepileptic drugs? N Engl J Med 2003; 348(15): 1480-2. [http://dx.doi.org/10.1056/NEJMe030023] [PMID: 12686705]

[7] Zimprich F, Sunder-Plassmann R, Stogmann E, et al. Association of an ABCB1 gene haplotype with pharmacoresistance in temporal lobe epilepsy. Neurology 2004; 63(6): 1087-9. [http://dx.doi.org/10.1212/01.WNL.0000141021.42763.F6] [PMID: 15452305]

[8] Sisodiya SM. Genetics of drug resistance. Epilepsia 2005; 46(Suppl. 10): 33-8. [http://dx.doi.org/10.1111/j.1528-1167.2005.00356.x] [PMID: 16359469]

[9] Lai M-L, Tien Y-E, Huang Y-S, Huang J-D. Studies on pharmacokinetic mechanism of phenytoin resistance in refractory epilepsy. J Pharm Sci 2013; 102(9): 3189-95. [http://dx.doi.org/10.1002/jps.23593] [PMID: 23658067]

[10] Escalante-Santiago D, Feria-Romero IA, Ribas-Aparicio RM, et al. MDR-1 and MRP2 gene polymorphisms in mexican epileptic pediatric patients with complex partial seizures. Front Neurol 2014; 5: 184 [http://dx.doi.org/10.3389/fneur.2014.00184] [PMID: 25346718]

[11] Uhr M, Tontsch A, Namendorf C, et al. Polymorphisms in the drug transporter gene ABCB1 predict antidepressant treatment response in depression. Neuron 2008; 57(2): 203-9. [http://dx.doi.org/10.1016/j.neuron.2007.11.017] [PMID: 18215618]

[12] Kimchi-Sarfaty C, Gribar JJ, Gottesman MM. Functional characterization of coding polymorphisms in the human MDR1 gene using a vaccinia virus expression system. Mol Pharmacol 2002; 62(1): 1-6. [http://dx.doi.org/10.1124/mol.62.1.1] [PMID: 12065748]

[13] Brinkmann U, Eichelbaum M. Polymorphisms in the ABC drug transporter gene MDR1. Pharmacogenomics J 2001; 1(1): 59-64. [http://dx.doi.org/10.1038/sj.tpj.6500001] [PMID: 11913728]

[14] Aller SG, Yu J, Ward A, et al. Structure of P-glycoprotein reveals a molecular basis for poly-specific drug binding. Science 2009; 323(5922): $1718-22$. [http://dx.doi.org/10.1126/science.1168750] [PMID: 19325113]

[15] Ambudkar SV, Kimchi-Sarfaty C, Sauna ZE, Gottesman MM. P-glycoprotein: From genomics to mechanism. Oncogene 2003; 22(47): 7468-85. [http://dx.doi.org/10.1038/sj.onc.1206948] [PMID: 14576852]

[16] Martin YN, Salavaggione OE, Eckloff BW, Wieben ED, Schaid DJ, Weinshilboum RM. Human methylenetetrahydrofolate reductase pharmacogenomics: Gene resequencing and functional genomics. Pharmacogenet Genomics 2006; 16(4): $265-77$. [http://dx.doi.org/10.1097/01.fpc.0000194423.20393.08] [PMID: 16538173] 
[17] Carr DF, Whiteley G, Alfirevic A, Pirmohamed M. FolATED study team, Investiga-tion of interindividual variability of the one-carbon folate pathway: A bioinformatic and genetic review. Pharmacogenomics J 2009; 9: 291-305. [http://dx.doi.org/10.1038/tpj.2009.29] [PMID: 19581920]

[18] Wei K, Sutherland H, Camilleri E, Haupt LM, Griffiths LR, Gan SH. Computational epigenetic profiling of CpG islets in MTHFR. Mol Biol Rep 2014; 41(12): 8285-92. [http://dx.doi.org/10.1007/s11033-014-3729-x] [PMID: 25213548]

[19] Liew SC, Gupta ED. Methylenetetrahydrofolate reductase (MTHFR) C677T polymorphism: Epidemiology, metabolism and the associated diseases. Eur J Med Genet 2015; 58(1): 1-10. [http://dx.doi.org/10.1016/j.ejmg.2014.10.004] [PMID: 25449138]

[20] Bellampalli R, Phani NM, Bhat KG, et al. Significance of 5,10-methylenetetrahydrofolate reductase gene variants in acute lymphoblastic leukemia in Indian population: An experimental, computational and meta-analysis. Leuk Lymphoma 2015; 56(5): $1450-9$. [http://dx.doi.org/10.3109/10428194.2014.953154] [PMID: 25115513]

[21] Desai M, Chauhan JB. Computational analysis for the determination of deleterious nsSNPs in human MTHFR gene. Comput Biol Chem 2018; 74: 20-30.

[http://dx.doi.org/10.1016/j.compbiolchem.2018.02.022] [PMID: 29524840]

[22] Xu YL, Li XX, Zhuang SJ, et al. Significant association of BDNF rs6265 G>A polymorphism with susceptibility to epilepsy: A metaanalysis. Neuropsychiatr Dis Treat 2018; 14: 1035-46. [http://dx.doi.org/10.2147/NDT.S154927] [PMID: 29713173]

[23] Shen T, You Y, Joseph C, et al. A review of its diagnostic and clinical relevance in neurodegenerative disorders. Aging Dis 2018; 9: 523-36. [http://dx.doi.org/10.14336/AD.2017.0717] [PMID: 29896439]

[24] Chufan EE, Sim HM, Ambudkar SV. Molecular basis of the polyspecificity of P-glycoprotein (ABCB1): Recent biochemical and structural studies. Adv Cancer Res 2015; 125: 71-96. [http://dx.doi.org/10.1016/bs.acr.2014.10.003] [PMID: 25640267]

[25] Altschul SF, Madden TL, Schäffer AA, et al. Gapped BLAST and PSI-BLAST: A new generation of protein database search programs. Nucleic Acids Res 1997; 25(17): 3389-402. [http://dx.doi.org/10.1093/nar/25.17.3389] [PMID: 9254694]

[26] Li W, Godzik A. Cd-hit: A fast program for clustering and comparing large sets of protein or nucleotide sequences. Bioinformatics 2006; 22(13): 1658-9.

[http://dx.doi.org/10.1093/bioinformatics/btl158] [PMID: 16731699]

[27] Jeanmougin F, Thompson JD, Gouy M, Higgins DG, Gibson TJ. Multiple sequence alignment with Clustal X. Trends Biochem Sci 1998; 23(10): 403-5. [http://dx.doi.org/10.1016/S0968-0004(98)01285-7] [PMID: 9810230]

[28] Ng PC, Henikoff S. SIFT: Predicting amino acid changes that affect protein function. Nucleic Acids Res 2003; 31(13): 3812-4. [http://dx.doi.org/10.1093/nar/gkg509] [PMID: 12824425]

[29] Adzhubei I, Jordan DM, Sunyaev SR. Predicting functional effect of human missense mutations using polyphen-2., Curr Protoc Hum Genet Chapter 7: Unit7.20, 2013.

[30] Capriotti E, Calabrese R, Casadio R. Predicting the insurgence of human genetic diseases associated to single point protein mutations with support vector machines and evolutionary information. Bioinformatics 2006; 22(22): 2729-34. [http://dx.doi.org/10.1093/bioinformatics/btl423] [PMID: 16895930]

[31] Berman HM, Westbrook J, Feng Z, et al. The protein data bank. Nucleic Acids Res 2000; 28(1): $235-42$. [http://dx.doi.org/10.1093/nar/28.1.235] [PMID: 10592235]

[32] Sali A, Blundell TL. Comparative protein modelling by satisfaction of spatial restraints. J Mol Biol 1993; $234(3)$ : 779-815. [http://dx.doi.org/10.1006/jmbi.1993.1626] [PMID: 8254673]

[33] Lovell SC, Davis IW, Arendall WB III, et al. Structure validation by Calpha geometry: Phi,psi and Cbeta deviation. Proteins 2003; 50(3): 437-50. [http://dx.doi.org/10.1002/prot.10286] [PMID: 12557186]

[34] Morris GM, Huey R, Lindstrom W, et al. AutoDock4 and AutoDockTools4: Automated docking with selective receptor flexibility. J Comput Chem 2009; 30(16): 2785-91. [http://dx.doi.org/10.1002/jcc.21256] [PMID: 19399780]

[35] Huey R, Morris GM, Olson AJ, Goodsell DS. A semiempirical free energy force field with charge-based desolvation. J Comput Chem 2007; 28(6): 1145-52.

[http://dx.doi.org/10.1002/jcc.20634] [PMID: 17274016]

[36] Kim S, Thiessen PA, Bolton EE, et al. Pubchem substance and compound databases. Nucleic Acids Res 2016; 44(D1): D1202-13. [http://dx.doi.org/10.1093/nar/gkv951] [PMID: 26400175]

[37] O’Boyle NM, Banck M, James CA, Morley C, Vandermeersch T, Hutchison GR. Open Babel: An open chemical toolbox. J Cheminform 2011; 3: 33 [http://dx.doi.org/10.1186/1758-2946-3-33] [PMID: 21982300] 
[38] Sayle RA, Milner-White EJ. RASMOL: Biomolecular graphics for all. Trends Biochem Sci 1995; $20(9): 374$. [http://dx.doi.org/10.1016/S0968-0004(00)89080-5] [PMID: 7482707]

[39] Chen G, Durán GE, Steger KA, et al. Multidrug-resistant human sarcoma cells with a mutant P-glycoprotein, altered phenotype, and resistance to cyclosporins. J Biol Chem 1997; 272(9): 5974-82 [http://dx.doi.org/10.1074/jbc.272.9.5974] [PMID: 9038218]

[40] Mickley LA, Lee J-S, Weng Z, et al. Genetic polymorphism in MDR-1: A tool for examining allelic expression in normal cells, unselected and drug-selected cell lines, and human tumors. Blood 1998; 91(5): 1749-56. [PMID: 9473242]

[41] Cascorbi I, Gerloff T, Johne A, et al. Frequency of single nucleotide polymorphisms in the P-glycoprotein drug transporter MDR1 gene in white subjects. Clin Pharmacol Ther 2001; 69(3): 169-74. [http://dx.doi.org/10.1067/mcp.2001.114164] [PMID: 11240981]

[42] Singhal NS, Sullivan JE. Continuous spike-wave during slow wave sleep and related conditions. ISRN Neurol 2014; $2014: 619079$. [http://dx.doi.org/10.1155/2014/619079] [PMID: 24634784]

[43] Inutsuka M, Kobayashi K, Oka M, Hattori J, Ohtsuka Y. Treatment of epilepsy with electrical status epilepticus during slow sleep and its related disorders. Brain Dev 2006; 28(5): 281-6. [http://dx.doi.org/10.1016/j.braindev.2005.09.004] [PMID: 16376508]

[44] Francois D, Roberts J, Hess S, Probst L, Eksioglu Y. Medical management with diazepam for electrical status epilepticus during slow wave sleep in children. Pediatr Neurol 2014; 50(3): 238-42. [http://dx.doi.org/10.1016/j.pediatrneurol.2013.11.002] [PMID: 24393416]

[45] Schneidman-Duhovny D, Inbar Y, Nussinov R, Wolfson HJ. PatchDock and SymmDock: Servers for rigid and symmetric docking. Nucleic Acids Res 2005; 33(Web Server issue): W363-7. [PMID: 15980490]

(C) 2018 Varghese and Palaniappan.

This is an open access article distributed under the terms of the Creative Commons Attribution 4.0 International Public License (CC-BY 4.0), a copy of which is available at: (https:/creativecommons.org/licenses/by/4.0/legalcode). This license permits unrestricted use, distribution, and reproduction in any medium, provided the original author and source are credited. 